\title{
RELACIONANDO AS CARACTERISTICAS E FUNÇÕES DO ORÇAMENTO COM A SATISFAÇÃO ORÇAMENTÁRIA EM EMPRESA DE CONSULTORIA EMPRESARIAL
}

\author{
RELATING THE CHARACTERISTICS AND FUNCTIONS OF THE BUDGET WITH BUDGETARY \\ SATISFACTION IN A BUSINESS CONSULTING COMPANY
}

\author{
IVAN RAFAEL DEFAVER| \\ Universidade Estadual do Oeste do Paraná - UNIOESTE \\ Mestrando em Contabilidade pela UNIOESTE, Campus de Cascavel (PR) \\ Orcid: https://orcid.org/0000-0002-7385-6948 / E-mail: ivandefaveri@hotmail.com \\ Endereço: Rua Universitária,1619 - Cascavel (PR) - CEP:85.859-110 \\ DIEGO GRAHL DE SANTI \\ Universidade Estadual do Oeste do Paraná - UNIOESTE \\ Mestrando em Contabilidade pela UNIOESTE, Campus de Cascavel (PR) \\ Orcid: https://orcid.org/0000-0002-7911-8241 / E-mail: diegograhlsanti@gmail.com

\section{LEANDRO AUGUSTO TOIGO} \\ Doutor em ciências contábeis e administração - FURB \\ Professor do mestrado em Contabilidade da UNIOESTE, Campus de Cascavel (PR) \\ Orcid: https://orcid.org/0000-0001-6198-8751 / E-mail: leandro.toigo@unioeste.br
}

\section{RESUMO}

O estudo investiga como as características, funções e satisfação orçamentária se relacionam em empresa de consultoria empresarial. Tendo as funções dos orçamentos e características designadas no processo nas organizações para controle gerencial. Estudos consideram inclusive que a satisfação dos usuários do orçamento é um efeito mediador da percepção de justiça que estes têm do processo orçamentário. A participação orçamentária representa o envolvimento dos gerentes e demais componentes na construção dos orçamentos e definição de metas orçamentárias. Para tanto, foi realizada uma pesquisa qualitativa, com entrevistas semiestruturadas aplicadas aos dois responsáveis pela coordenação do processo orçamentário de uma empresa localizada na cidade de Cascavel - PR. Os resultados indicam algumas características e funções apresentadas pelo processo orçamentário na empresa, e também fatores condicionantes de satisfação apresentados pelos participantes. Dentre os fatores mais relacionados com a satisfação estão aqueles relativos ao engajamento do funcionário com a empresa, como a participação e a avaliação de desempenho por meio do processo orçamentário, uma vez que os responsáveis pelo processo se mostram satisfeitos sobretudo pela possibilidade de estarem envolvidos, mostrando voz ativa e tomando parte no processo de gestão. $O$ trabalho contribuiu na definição de fatores capazes de gerar satisfação no processo orçamentário, de modo a permitir uma visão que pode ser aplicada nas empresas, de forma a proporcionar processos mais viáveis para as organizações. Estudos futuros podem investigar o fenômeno por meio de uma perspectiva quantitativa, também testando a satisfação orçamentária como uma variável endógena.

Palavras-chave: Características do Orçamento; Funções do Orçamento; Satisfação com o Orçamento . 


\begin{abstract}
The study investigates how features, functions, and budget satisfaction relate to a businessconsulting firm. Having the functions of the budgets and characteristics assigned in the process in the organizations for managerial control. Many studies also consider that the satisfaction of budget users is a mediating effect of their perception of the justice of the budget process. Budget participation represents the involvement of managers and other components in the construction of budgets and the definition of budget goals. For that, a qualitative research was conducted, with semi - structured interviews applied to the two responsible for coordinating the budget process of a company located in the city of Cascavel - PR. The results indicate some characteristics and functions presented by the budget process in the company, as well as satisfaction conditioning factors presented by the participants. Among the factors most related to satisfaction are those related to the engagement of the employee with the company, such as participation and performance evaluation through the budget process, since those responsible for the process are satisfied mainly by the possibility of being involved, showing active voice and taking part in the management process. The work contributed to the definition of factors capable of generating satisfaction in the budget process, in order to allow a vision that can be applied in the companies, in order to provide more viable processes for the organizations. Future studies can investigate the phenomenon through a quantitative perspective, also testing budget satisfaction as an endogenous variable.
\end{abstract}

Keywords: Budget Characteristics; Budget Functions; Satisfaction with the Budget.

\title{
1 INTRODUÇÃO
}

Dentro da esfera dos sistemas de controles gerenciais (SCG), os orçamentos se mostram como uma das ferramentas de maior relevância e abordagem, tanto teórica quanto prática (SIMONS, 1995; BEDFORD; MALMI, 2015). Dentro da perspectiva do modelo de Alavancas de Controle proposto por Simons (1995), os orçamentos correspondem a principal ferramenta dos sistemas de controle diagnóstico, responsável por monitorar e avaliar desempenho e a eficiência do negócio, como apoio a alta gestão (COVALESKI; AIKEN, 1986; CANONICO; SODERLUND, 2010). No entanto, estudos mais recentes trazem o fato de os orçamentos adotarem, dentro do mesmo modelo, a função de sistemas interativos, ao proporcionarem a flexibilização de processos (FROW; MARGINSON; OGDEN, 2010).

Essa amplitude na utilização dos orçamentos faz com que eles sejam um instrumento abrangente, com diversas características e funções dentro das organizações (SPONEM; LAMBERT, 2016). Essas características dos orçamentos têm diversos reflexos, tanto positivos quanto negativos (SPONEM; LAMBERT, 2016), no entanto, os estudos na área tendem a não abordar essas diferentes características conjuntamente (SHIELDS; SHIELDS, 1998), como um pacote de informações de controle (MALMI; BROWN, 2008), mas apenas centram-se em uma característica especifica dos orçamentos (SPONEM; LAMBERT, 2016), mesmo ao se considerar que o uso conjunto de diversas características dos orçamentos, ou então voltado para várias funções distintas ao mesmo tempo, tende a ter efeitos positivos mais relevantes (HANSEN; VAN DER STEDE, 2004).

As funções dos orçamentos nas organizações, dentro da perspectiva dos sistemas de Simons (1995), incluem o planejamento operacional, comunicação de objetivos, avaliação do desempenho e formação de estratégia (HANSEN; VAN DER STEDE, 2004), não havendo, no 
entanto, um sistema padrão adequado a todas as empresas (BEDFORD; MALMI, 2015). Essas diferentes funções dos orçamentos, bem como as características adotadas por eles na organização (CHAPMAN; KIHN, 2009), podem ter influência direta não só na performance da empresa, como também na satisfação dos usuários (SHIELDS; SHIELDS, 1998).

Estudos como o de Maiga (2006) consideram inclusive que a satisfação dos usuários do orçamento é um efeito mediador da percepção de justiça que estes têm do processo orçamentário. Isto posto, percebe-se o fato de as características e funções designadas dos orçamentos terem um impacto, de forma tanto direta quanto indireta (MAIGA, 2006), no desempenho geral da empresa (CHAPMAN; KIHN, 2009), por meio da influência desse processo no comportamento dos membros da organização (MERCHANT, 1981).

Diversos outros estudos já abordaram as características dos orçamentos, com foco no papel do orçamento como ferramenta de controle gerencial (COVALESKI; AIKEN, 1986; CANONICO; SODERLUND, 2010; BEDFORD; MALMI, 2015), outros abordaram a questão das múltiplas dimensões dos orçamentos (HANSEN; VAN DER STEDE, 2004; FROW; MARGINSON; OGDEN, 2010). Há ainda estudos que abordaram questões comportamentais dos orçamentos (MERCHANT, 1981; FISHER; FREDERICKSON; PEFFER, 2002; MAIGA, 2006). O estudo de Sponem e Lambert (2016), por sua vez, buscou examinar como as diferentes características e funções dos orçamentos dentro das organizações afetam a satisfação dos usuários desses orçamentos. A relevância desse estudo se dá sobretudo pela indicação de quais as características e funções dos orçamentos tem um impacto mais positivo ou negativo nos indivíduos envolvidos no processo de planejamento e execução orçamentária, já que, conforme Merchant (1981) e Maiga (2006), isso tem reflexo no comportamento e desempenho desses envolvidos.

Assim, ao se considerar o fato de Sponem e Lambert (2016) terem aplicado seu estudo em empresas francesas, torna-se relevante verificar os efeitos das caraterísticas e funções do orçamento na satisfação dos usuários no contexto brasileiro, para identificar se a forma como os orçamentos são desenvolvidos no território nacional, bem como as características individuais dos brasileiros causam efeitos diversos na satisfação desses em relação ao processo orçamentário.

O setor de serviços tem hoje uma importante representação para a economia brasileira, contendo alguns segmentos intensivos em conhecimento e tecnologia, de modo a tornarem-se vetores de inovação para outros setores da economia (SILVA, 2006)

Dessa forma, o estudo levanta a seguinte questão de pesquisa: Como as características e funções do orçamento afetam a satisfação orçamentária em uma organização de consultoria empresarial? E como forma de responder a essa questão, o estudo tem como objetivo analisar de que forma as características e funções do orçamento afetam na satisfação orçamentária na organização.

Para atender a esse objetivo, além da presente introdução, o estudo conta ainda com a revisão da literatura, abordando estudos anteriores sobre caracterização e funções dos orçamentos e satisfação dos usuários, metodologia, explanando o desenho da pesquisa, além da análise dos resultados e das considerações finais do estudo.

\section{REFERENCIAL TEÓRICO}

Nessa seção é retratada a base teórica do presente estudo. São apresentados os conceitos e discussões referentes as características dos orçamentos, as funções que estes exercem na administração, para identificar a relação dessas configurações com a satisfação orçamentária. 


\subsection{CARACTERÍSTICAS DOS ORÇAMENTOS}

Os orçamentos podem ser reconhecidos como um conjunto de ferramentas de controle (MALMI; BROWN, 2008), de modo a agrupar uma série de características e dimensões distintas (SHIELDS, SHIELDS, 1998). A literatura já descreve essas características (CHAPMA; KIHN, 2009; VAN DER STEDE, 2001), de modo a ser utilizado nesse estudo o constructo de características elencado por Sponem e Lambert (2016).

Esses autores, por meio de entrevista em grupo focal com CEOs (Chief Executive Officers) e CFOs (Chief Financial Officers), identificaram um total de 11 características presentes nos processos orçamentários das empresas, sendo essas a participação orçamentária, negociação entre os componentes da organização, dificuldade de implantação, variância entre o real e o orçado, reformulação, revisão e avaliação dos orçamentos, recompensas por desempenho, envolvimento dos componentes com o processo orçamentário, detalhamento e formalização dos orçamentos (SPONEM; LAMBERT, 2016).

As características de participação e negociação correspondem a fase anterior a aplicação dos orçamentos, o planejamento das ações. A participação orçamentária representa o envolvimento dos gerentes e demais componentes na construção dos orçamentos e definição de metas orçamentárias (SHIELDS; SHIELDS, 1998; DERFUSS, 2009). Já a negociação corresponde a alinhamento de interesses entre superiores e subordinados na construção dos orçamentos, de modo a criar uma interdependência entre os objetivos e ações destes (FISHER; FREDERICKSON; PEFFER, 2006).

A fase da condução do orçamento, que representa a ação orçamentária propriamente dita, é onde se encontram as características de dificuldades, variância e revisão. A dificuldade representa a viabilidade de se operacionalizar as metas orçamentárias, ou seja, o quão difícil é para os gestores realizarem efetivamente os orçamentos (MERCHANT; MANZONI, 1989). A variância representa o gap entre os valores orçados e realizados, de modo a se direcionar a responsabilidade para o gestor competente (SPONEM; LAMBERT, 2016). Já a característica de revisão representa, de acordo com Sponem e Lambert (2016), a faculdade em se alterar o orçamento durante o período.

Já as características de reformulação, avaliação e recompensas corresponde a terceira fase do processo orçamentário, a fase de revisão e avaliação, que ocorre após a ação do orçamento. A característica de reformulação representa a capacidade de se alterar os orçamentos de acordo com a viabilidade ou não de se alcançar os orçamentos ou para alinhamento com alterações no plano estratégico (SPONEM; LAMBERT, 2016). A característica de avaliação corresponde ao uso dos orçamentos como meio de medir o desempenho dos gestores, a partir de resultados contábeis e financeiros comparados as metas orçamentárias (OTLEY; FAKIOLAS, 2000). Já as recompensas representam a característica do orçamento de ser parâmetro para definição de recompensas por desempenho aos gestores (VAN VEENDIRKS, 2010).

A última fase do processo orçamentário, representada pelas características de envolvimento da alta administração, detalhamento e formalização do orçamento, corresponde as características transversais dos orçamentos (SPONEM; LAMBERT, 2016). O envolvimento representa a participação da alta gerência da empresa nas decisões orçamentárias, ou seja, seu envolvimento na estipulação de metas e acompanhamento dos orçamentos (ABERNETHY; BROWNELL, 1999). O detalhamento, de acordo com Sponem e Lambert (2016), representa a quantidade de informações constante na peça orçamentária, possibilitando maior compreensão do mesmo. Já a formalização é a característica relativa à 
utilização de regras e procedimentos formalizados para a constituição do orçamento (UENO; SEKARAN, 1992).

Dessa forma, conhecendo as características dos orçamentos, torna-se relevante identificar também quais as suas funções dentro das organizações, e como essas funções se alinham a essas particularidades elencadas por Sponem e Lambert (2016).

\subsection{FUNÇÕES DO ORÇAMENTO}

O orçamento desempenha uma série de funções dentro das organizações, sendo desenvolvido de forma a possibilitar a análise das diferentes etapas e papéis. Ao todo, os autores Sponem e Lambert (2016) elencam 11 diferentes funções dos orçamentos, sendo elas avaliação do desempenho do gerente, definição de responsabilidades e compromissos contratuais, comunicação entre vários níveis de gestão, implantação de estratégias, previsão de necessidades financeiras, gerenciamento de riscos, coordenação de várias operações, direção de diferentes atividades comerciais da empresa, autorização de gastos, alocação de recursos e comunicação com partes interessadas externas (acionistas, credores).

Essas funções dos orçamentos nas organizações têm basicamente quatro principais usos, sendo eles o orçamento para acionistas, o orçamento administrativo, orçamento gerencial e o orçamento estratégico (SPONEM; LAMBERT, 2016).

Quanto ao orçamento para acionistas, Derfuss (2009) mostra que o nível de críticas relacionadas ao uso do orçamento para avaliar e recompensar os gerentes é menor quando a avaliação é acompanhada de outras práticas orçamentárias. Com isso, os orçamentos não são só utilizados para controlar, mas desempenham um papel na definição da estratégia estabelecido pelo alto escalão.

Essa modalidade de orçamento destina-se a mobilizar tanto a gestão de topo como a operacional na definição de estratégias de longo prazo, e incentivando esses gestores a seguir de perto sua implantação no curto prazo. (SPONEM; LAMBERT, 2016).

No que tange ao orçamento para fins administrativos, este tende a ser menos criticado quando o nível de participação na administração entre o gerente operacional, o envolvimento da alta gerência e a importância atribuída aos planos de ação durante as negociações orçamentárias são elevadas (LIBBY; LINDSAY, 2010).

Chong e Mahama (2014) confirmam a importância de participação e envolvimento dos gestores junto a administração para ter satisfação na elaboração e na execução do orçamento.

Já a etapa gerencial diz respeito aos planos relacionados à estruturação das atividades da organização, (FREZATTI, 2009) sendo a base de todo o processo orçamentário de uma empresa. Sponem e Lambert, 2016 destacam que o orçamento coercivo serve uma abordagem de gerenciamento por objetivos. Desse modo, Arwidi e Samuelson (1993) comentam que, o orçamento interativo é usado tanto como uma ferramenta de gerenciamento quanto como ferramenta estratégica, tendo ligação direta entre ambos no controle orçamentário

Por fim, quando utilizado para fins estratégicos, o orçamento deve ser desenvolvido de forma consistente com a ideia de disciplina orçamental, de modo a comunicação de objetivos e formação de estratégias ter base legal para a atingir as metas proposta pela administração (HOPE; FRASER, 2003).

De acordo com Sponem e Lambert (2016), o orçamento solto é uma ferramenta para implementar a estratégia, onde destacam que o orçamento interativo funciona como uma ferramenta central para estruturar as negociações e discutir escolhas estratégicas. 
Dentro do orçamento estratégico temos as prioridades do orçamento (HANSEN; VAN DER STEDE, 2004), que devem ser consistentes com os conceitos de orçamentação, eficiência e o seu impacto analisado numa perspectiva de longo prazo.

Assim, para Sponem e Lambert (2016), a discussão dos orçamentos baseados sobre planos de ação e os objetivos estratégicos é mais satisfatória do que a discussão dos orçamentos apenas em nível financeiro.

Conhecendo-se, portanto, quais as características apresentadas pelos orçamentos, e quais as principais funções desempenhadas por eles nas empresas, é relevante discutir como estes impactam na satisfação de seus usuários dentro das organizações.

\subsection{SATISFAÇÃO COM O ORÇAMENTO}

As características implícitas ao orçamento dentro de uma organização, bem como os usos e funções dados a eles por estas exercem influência na forma como os componentes dessa organização se sentem em relação a ele (SPONEM; LAMBERT, 2016). Dessa forma, os autores Sponem e Lambert (2016) elencam 11 características que essencialmente afetam a satisfação dos usuários dos orçamentos com o processo e usos dos mesmos.

Ao se considerar o alinhamento entre as características e funções dos orçamentos com a satisfação que estes podem gerar nos usuários, os 11 fatores elencados por Sponem e Lambert (2016) são: suscitar comportamentos oportunistas, diminuir a cooperação, ser adequado ou não em um ambiente de incerteza, ser muito rígido, impor uma cultura de controle ou uma cultura de engajamento, impedir ou propor a inovação, ser principalmente um ritual, levar muito tempo e agregar pouco valor, traduzir a predominância da rentabilidade a curto prazo em detrimento da criação de valor a longo prazo, cobrir um período de tempo adequado ou não ao ciclo comercial da empresa.

Dessa forma, os orçamentos podem ter diversos níveis de satisfação dentro das organizações, indo desde satisfação limitada, pouca, satisfeito, mas considerando efeitos adversos ou sendo considerando uma importante ferramenta de gestão, logo, suscitando a satisfação nos usuários (SPONEM; LAMBERT, 2016).

É importante ressaltar que os diferentes níveis e tipos de satisfação são vinculadas às funções e às características dos orçamentos, uma vez que a junção de determinada função com determinada característica, pode gerar um tipo específico de satisfação, ou, ao contrário, reduzir a satisfação, podendo gerar inclusive a insatisfação dos usuários.

Desse modo, na sequência, são apresentados os resultados de alguns assuntos sobre a temática, em vista a se esclarecer e exemplificar esse relacionamento entre características, funções e satisfação orçamentários.

\subsection{ESTUDOS ANTERIORES}

Outros estudos já buscaram abordar as funções do orçamento e a satisfação gerada por esse orçamento. Entre esses estudos, se dá destaque para o de Sponem e Lambert (2016), o qual buscou propor uma configuração orçamentária que permitisse a associação entre as características de cada modelo orçamentário e as funções desempenhadas por este dentro da organização, com a satisfação orçamentária gerada por essa associação. Os autores aplicaram questionários aos gestores financeiros e contadores gerenciais de diversas empresas de capital aberto, tendo obtido 269 questionários válidos. Com o uso de técnicas multivariadas de dados e da realização de análise qualitativa dos resultados, os autores desenvolveram uma tipologia com cinco configurações orçamentárias, capazes de identificar e relacionar as 
características e usos dos orçamentos e proporcionar a criação de satisfação com o orçamento. São essas configurações: o orçamento de referência, o orçamento coercivo, o orçamento interativo, o orçamento frouxo e o orçamento indicativo.

Outro estudo que buscou avaliar a influência das características orçamentárias no impacto que estas têm no indivíduo foi o Derfuss (2009). O autor se propôs realizar uma metaanálise de diversos trabalhos publicados em busca dessa relação, a fim de identificar se os resultados encontrados por tais pesquisas podem ser confirmados ou refutados. Entre outros resultados do estudo, se destaca a conclusão de que determinadas configurações orçamentárias refletem no comportamento e satisfação dos usuários, influenciando nas ações e no comportamento dos gestores e criando valor para a companhia. Derfuss (2009) ressalta esse resultado como sendo a provável causa de as empresas manterem a adoção de orçamentos, mesmo tendo em vista as críticas e desvantagens feitas a essa ferramenta de controle. Já o estudo de Maher, Fakhar e Karimi (2018) buscou avaliar a relação entre a ênfase e o planejamento orçamentário com o desempenho organizacional e como isso pode refletir na satisfação dos usuários. Através de técnicas de análise multivariadas de dados, os autores confirmaram a hipótese de relação válida entre a ênfase dada ao orçamento (funções) e o planejamento orçamentário (características), com a satisfação orçamentária e com o desempenho, tanto organizacional quanto gerencial. Os resultados permitem aos autores concluírem pelas configurações orçamentárias mais adequadas, a fim de aumentar a satisfação dos usuários com o processo orçamentário, e, assim, melhorar o desempenho da empresa como um todo.

Com base no exposto, a próxima seção apresenta o desenho metodológico do trabalho, com base nas variáveis apresentadas e nas relações exploradas a partir da literatura revisada.

\section{METODOLOGIA}

A metodologia utilizada no presente trabalho é o estudo de caso. Conforme a classificação de Bonoma (1985), o estudo de caso corresponde a um processo qualitativo, com abordagem indutiva, que visa sobretudo a observação generalizada de fatos, delimitação e categorização desses fatos e validação teórica de um fenômeno. Bruyne, Herman e Schoutheete (1977) indicam ainda que o estudo de caso é um método que visa reunir informações numerosas e detalhadas sobre uma situação, com intuito de aprender e analisar tal situação com profundidade.

Nesse sentido, justifica-se a utilização de tal método nessa pesquisa por se objetivar conhecer com profundidade como as características e funções do orçamento em uma única organização, localizada na cidade de Cascavel - PR, afetam a satisfação dos usuários dos orçamentos nessa organização. A escolha de tal empresa se deu por diversos fatores. Sendo uma empresa de prestação de serviços de consultoria, a empresa detém grande familiaridade com os orçamentos, uma vez que desenvolve seus próprios orçamentos com adequado rigor, e os toma como modelo para a construção e sugestão dos orçamentos para seus clientes. A disponibilidade de acesso aos pesquisadores à empresa, bem como pela sua relevância no contexto econômico da cidade também foram fatores que motivaram sua escolha para a pesquisa.

Para a execução da pesquisa, foram utilizadas entrevistas qualitativas semiestruturadas, observação de procedimentos e análise de documentos relacionados ao processo orçamentário (Yin, 2010), com vistas a triangular os dados para confirmá-los e permitir a profundidade da análise. Para a análise das entrevistas, foi utilizado o método da 
análise de conteúdo, seguindo para tanto a metodologia de análise proposta por Bardin (2011).

O roteiro de entrevista foi elaborado a partir da adaptação do questionário utilizado na pesquisa de Sponem e Lambert (2016). As entrevistas foram previamente agendadas com duas pessoas responsáveis pela elaboração e também pela aplicação dos orçamentos dentro da organização, sendo ambos líderes de grupos responsáveis pelas atividades operacionais da empresa, tendo a primeira entrevista tido duração de aproximadamente 24 minutos, e a segunda entrevista duração de 29 minutos. As entrevistas foram gravadas em forma de áudio, e posteriormente transcritas integralmente com o uso do software MS Word ${ }^{\circledR}$ e codificados com auxílio do software Atlas.ti 8.0.43. Para a criação da wordcloud foi utilizada a ferramenta online wordart.com.

Dessa forma, a próxima seção pretende apresentar os dados referentes a empresa, o perfil dos respondentes, para poder proceder-se com a análise das entrevistas com vistas a atingir os objetivos da pesquisa.

\section{DESCRIÇÃO E ANÁLISE DOS DADOS}

Nessa seção, são transcorridas as entrevistas realizadas, contextualizando a empresa e os respondentes, e apresentando os resultados das falas, bem como, posteriormente, sendo realizada a análise das falas como forma de se identificar os relacionamentos propostos pelo estudo.

\subsection{DESCRIÇÃO DA ORGANIZAÇÃO}

A organização objeto do estudo é uma empresa que atua no ramo de consultoria empresarial. A empresa foi fundada em 2002 na cidade de Curitiba, no Paraná, onde fica sua sede, e possui escritórios nas cidades de Cascavel e Maringá, com autonomia administrativa em relação a matriz, atuando também em outros cinco estados do Brasil. O escritório de Cascavel é gerido por dois sócios da empresa, e tem cerca de 30 funcionários, atuando em diversas funções. O escritório realiza um processo orçamentário próprio, coordenado por dois funcionários do setor de consultoria.

Os dois responsáveis pelo processo orçamentário possuem ensino superior completo em Ciências Contábeis e MBA na área de gestão, um atuando no cargo de consultor pleno (entrevistado 1) e outro sendo o coordenador do departamento de consultoria (entrevistado 2), atuando, respectivamente, a 6 e 12 anos na empresa. Ressalta-se também a idade dos responsáveis, com 24 e 30 anos, respectivamente, indicando o fato de a diretoria da empresa ceder a responsabilidade do processo orçamentário a pessoas mais novas, com maior conhecimento de técnicas e procedimentos mais atualizados na área de gestão, mas ao mesmo tempo, com maior tempo de atuação dentro da organização, a fim de conhecer os processos da empresa.

\subsection{ANÁLISE DOS DADOS}

\subsubsection{Características Dos Orçamentos}

Dando início as análises da pesquisa, foi montada a Figura 1, no software Atlas.ti, mostrando o relacionamento das categorias das dimensões com as categorias de análise do 
construto da pesquisa, com o intuito de auxiliar os pesquisadores na organização das análises, auxiliando na condução do processo.

Figura 1: Relacionamento de dimensões da categoria características dos orçamentos.

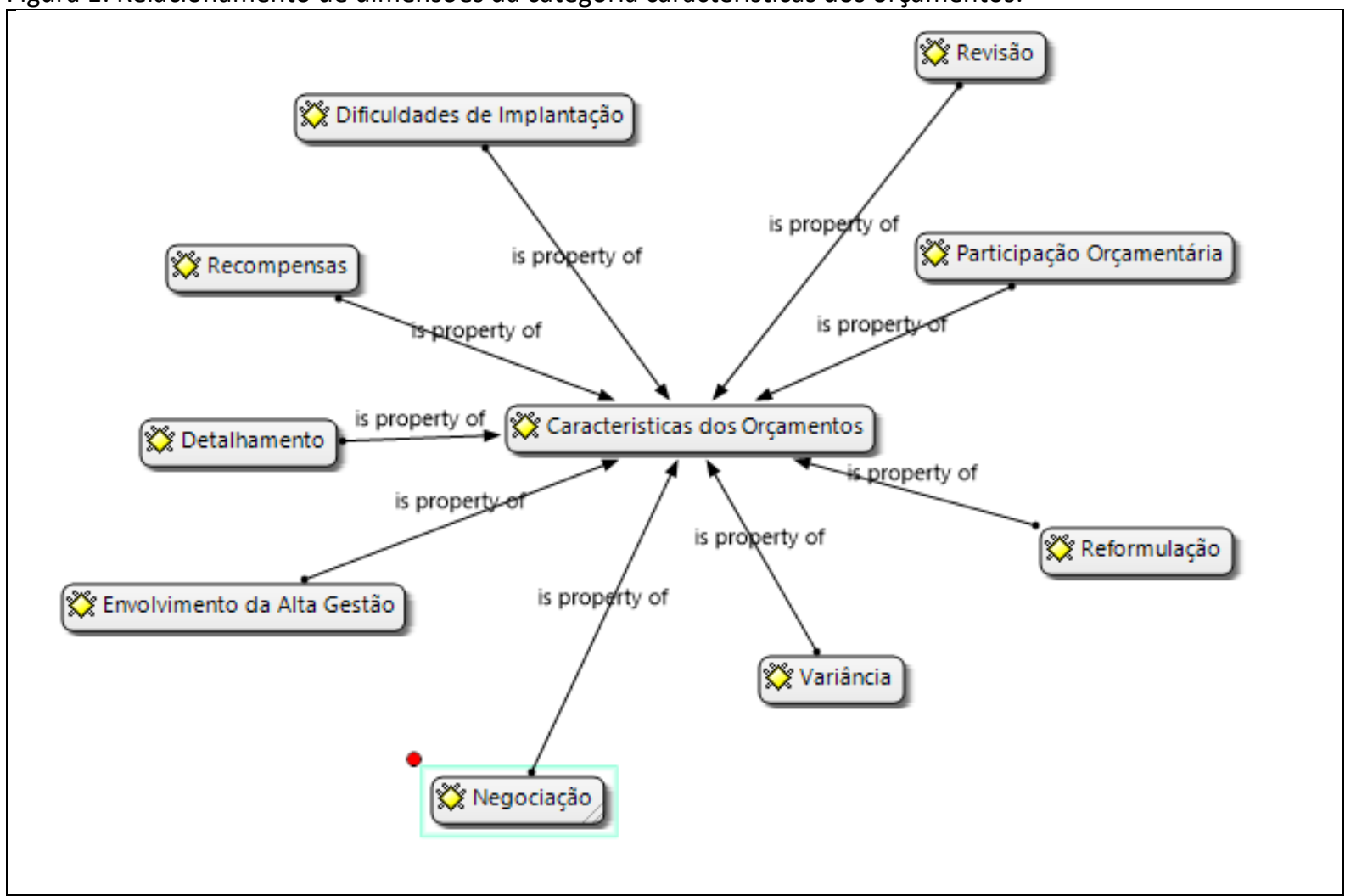

Fonte: os autores (2018).

Indagados sobre a categoria de características dos orçamentos, ambos os respondentes indicaram que o processo inclui forte participação dos componentes da organização. O processo da empresa é dividido em contas, as quais são designadas aos gestores relativos ao setor ao qual pertence aquelas contas. Esses gestores indicam quais os gastos necessários para a execução de suas tarefas e o volume necessário desses gastos. Tais valores são utilizados para a formalização de planos de ação dentro da organização, de modo que esses gestores recebem tal autonomia tendo em vista serem os responsáveis por aquelas áreas, e, portanto, deterem o conhecimento de como funciona e dos gastos referentes a seus setores.

De acordo com os entrevistados, esse processo de participação melhora a alocação de recursos dentro da empresa, fato que fica evidente na fala do Entrevistado 2:

Com essa nova metodologia que a gente está aplicando, a gente está dando mais
foco inclusive em reuniões trimestrais com apresentação do plano de ação para
todos da empresa, e fazendo apontamentos de onde está passando, de onde a gente
está com folga orçamentaria, tentando sempre trazer uma resposta, se passou
porque, se não passou porque, se sobrou dinheiro, porque que sobrou.

Isso posto, se corroboram os achados de Derfuss (2009), que indica o fato de os orçamentos participativos permitirem maior flexibilidade na ação dos gestores, o que também auxilia na melhora dos processos e redução dos gastos.

Apesar da participação orçamentária ser uma característica marcante na organização, a negociação dos orçamentos entre os gestores e a diretoria não mostra-se muito presente, 
uma vez que, de acordo com os respondentes, as metas orçamentárias delimitadas pelos gestores necessitam de justificativas objetivas, de modo a não corresponder a característica de alinhamento de interesses descrita por Fisher, Frederickson e Peffer (2006), pois, mesmo os gestores participando ativamente da construção dos orçamentos, o foco reside principalmente nos interesses da organização, e não busca atender aos interesses dos gestores.

Os entrevistados também consideraram não haver dificuldades na implantação dos orçamentos, devido às metas orçamentárias tenderem a ser sempre atingidas, indicando, conforme Merchant e Manzoni (1989), que as metas orçamentárias estabelecidas se mostram viáveis em sua operacionalização. No que diz respeito às variações entre valores orçados e realizados, o Entrevistado 1 indica que "o primeiro passo é acontecer o porquê aconteceu aquilo, terminou o mês por exemplo, e a gente viu que teve este aumento brusco, a gente vai ver o porquê com a pessoa que está executando as despesas, o porquê que ocorreu aquilo".

Esse processo da organização corrobora com Sponem e Lambert (2016), uma vez que, quando ocorrem variações expressivas, os coordenadores do projeto buscam verificar quem foi o responsável pelas contas em que tal variação foi vista, para então identificar qual a causa dessa variação, se erro no estabelecimento das metas, se má gestão dos gastos. Outra característica presente nos orçamentos da organização estudada é a da faculdade de reformulação, pois, de acordo com os entrevistados, ocorre um processo periódico de revisão dos orçamentos, com vistas a avaliar a concretude das metas orçadas com os valores que vem sendo realizados pela empresa.

Quanto ao processo de revisão e ajustes no orçamento, o Entrevistado 1 indica que:

a cada seis meses é feito uma revisão, a gente senta a cada três meses, mais é revisto somente para ver se está tudo ok, o acompanhamento que a gente faz é mensal, os gestores do pacote fazem isso mensalmente, a cada três meses a empresa se reúne para dar uma olhada e a cada a seis meses a gente verifica se a necessidade de refazer ou não, se a empresa está naquele cenário ou não.

A partir dessas reuniões os membros da diretoria da empresa tendem a avaliar o desempenho dos gestores, averiguando a conformidade da execução do orçamento com o orçado, conforme indicado por Otley e Fakiolas (2000) e Sponem e Lambert (2016). Já no sentido de remuneração, o orçamento não possui essa característica diretamente na organização investigada, conforme indicado pelo Entrevistado 2: "remuneração variável é baseada no resultado de fato ocorrido, na DRE (resultado) que a gente atingiu efetivamente, não com base no orçamento". Desse modo, a remuneração variável não é realizada conforme o indicado por Van Veen-Dirks (2010), de modo individual de acordo com o desempenho do gestor, mas sim a partir do resultado geral da organização.

Os entrevistados indicam ainda a questão do detalhamento e formalização dos orçamentos, de modo que todas as contas são extremamente detalhadas, os valores orçados são determinados a partir de previsões formais de aumento de mercado, considerando o crescimento tanto das receitas quanto das despesas, corroborando assim com Sponem e Lambert (2016), ao indicarem que estas características contribuem para uma melhor compreensão e aplicação dos orçamentos. 


\subsubsection{Funções dos orçamentos}

Para auxiliar a condução das análises da segunda categoria de análise do estudo, relativa as funções do orçamento, foi construída a Figura 2.

Figura 2: Relacionamento de dimensões da categoria funções do orçamento.

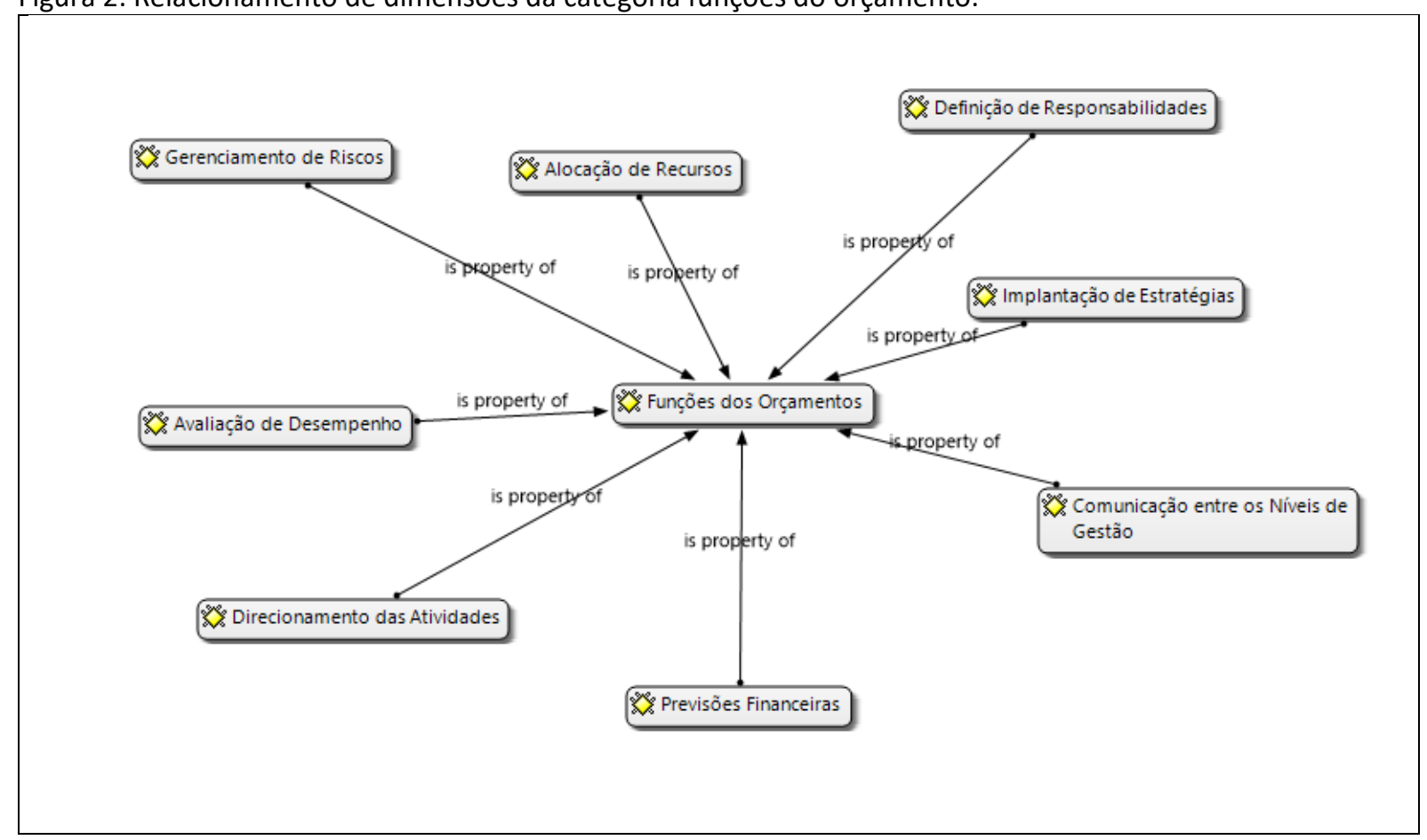

Fonte: os autores (2018).

No que tange as funções do orçamento dentro da organização, os responsáveis pelo processo orçamentário foram questionados sobre a utilização do orçamento, com fins a identificar as múltiplas funções dos orçamentos elencadas por Sponem e Lambert (2016). 0 Entrevistado 2 coloca que:

para mensurar como a gente está indo em relação ao resultado principalmente, então o principal uso do orçamento é saber se a gente está indo no caminho certo, se estamos gastando muito ou pouco, controlando os nosso recursos, [...] se a gente está gastando sem saber onde, então a gente acaba utilizando o orçamento para ver.

Já o Entrevistado 1 indica que:

primeiro para parte financeira, obviamente para controle financeiro, fluxo de caixa, e em segundo momento eu diria que é para parte estratégica, eles utilizam informações do orçamento para definir a parte estratégica, nível de desempenho de funcionários, de colaboradores, eles utilizam isso para ver se o cara está engajado, se tá comprometido com a empresa, eu diria que são estas três frentes aí.

Essas informações confirmam a utilização dos orçamentos como meio de avaliar o desempenho individual dos gestores, ao identificar o alcance das metas e também se os recursos orçados estão sendo alocados nos locais corretos, confirmando a função chamada por Derfuss (2009) e Sponem e Lambert (2016) de uso por acionistas, onde os diretores da empresa se valem do orçamento como ferramenta de controle diagnóstico, a fim de avaliar e controlar o desempenho dos gestores.

A estruturação dos orçamentos em pacotes de contas, os quais são designados para gestores que recebem a responsabilidade de gerir aquele pacote específico, indicada por 
ambos os entrevistados, indica outra função do uso por acionistas dos orçamentos, que consiste na definição e distribuição de responsabilidades.

Quanto a função de integração entre os diversos níveis operacionais, percebe-se sua aplicação na organização, uma vez que ambos os entrevistados indicaram a elaboração de planos de ação prévios com vistas a determinar os meios para o alcance das metas orçamentárias (LIBBY; LINDSAY, 2010). Outro fator indicado, que corrobora com Sponem e Lambert (2016), é a integração da direção com a parte operacional, apesar de ambos os entrevistados considerarem esse um uso mais difícil e restrito, também consideram a capacidade de buscar integrar o profissional as atividades da empresa, sobretudo com a designação de valores dentro dos orçamentos para a capacitação profissional.

Outro ponto a ser ressaltado está na função estratégica do orçamento dentro da empresa. Corroborando com a visão de Arwidi e Samuelson (1993) de que o orçamento pode atuar como uma ferramenta de controle interativo, ambos entrevistados indicaram o fato de os orçamentos serem utilizados como base para a definição das estratégias da empresa. 0 entrevistado 1 indica que "na parte de estratégica, eu diria que é o principal, quando a diretoria reúne o nível tático para fazer o plano de ações de estratégia da empresa, [...], qual o cenário a empresa busca atingir, esse seria o principal no nosso planejamento estratégico". No mesmo sentido, o entrevistado 2 indica que:

A gente acaba traçando a estratégia no que temos disponível para gastar, [...], então o planejamento estratégico e o orçamento trabalham juntos, e a gente sempre trabalha com cenários, se temos fluxos de caixa para orçar estes investimentos.

Desse modo, todas as estratégias adotadas pela empresa tomam como base os valores e atividades disponíveis dentro dos orçamentos, corroborando assim com Hope e Fraser (2003), que indicam o fato de os orçamentos darem base para a formulação de estratégias e o alcance das metas da organização.

Dessa forma, pode-se notar nas falas dos entrevistados três dos quatro usos dos orçamentos definidos por Sponem e Lambert (2016), sendo eles o orçamento para acionistas, o orçamento gerencial e o orçamento estratégico, não sendo percebido o orçamento administrativo. Já das 11 funções elencadas pelos autores, pode-se perceber o uso dos orçamentos para a avaliação de desempenho, comunicação entre os níveis organizacionais, definição de responsabilidades e implantação de estratégias, o que leva ao terceiro bloco de análise, que avalia a satisfação dos responsáveis com o processo orçamentário da empresa.

\subsubsection{Satisfação}

Já para o auxílio da condução das análises da terceira categoria da pesquisa foi construída a Figura 3. Dentre os fatores que indicam a satisfação dos responsáveis com o processo orçamentário da empresa, ficaram implícitos nas falas dos entrevistados sobretudo a cultura do engajamento, pois, conforme o entrevistado 1 indicou "quando a gente participa a gente se sente dono também, a gente se sente parte daquilo, uma segunda vantagem é o conhecimento que a gente adquire, podendo aplicar em outras empresas, isso é muito bom, o próprio ambiente da empresa melhora" também o fato de melhorar a cooperação entre os colegas de trabalho e a flexibilidade do processo.

Já o entrevistado 2 considera sua satisfação ligada sobretudo a melhoria nos processos administrativos e como uma ferramenta eficaz de tomada de decisões: "a gente está utilizando um orçamento eficaz, que ele acaba servindo como ferramenta para tomada de decisões e controle administrativo para os gastos da empresa, então eu considero satisfeito", 
corroborando com Sponem e Lambert (2016) ao indicar que o principal ponto de satisfação está em o orçamento não ser simplesmente um ritual, mas sim ter um papel ativo dentro da organização.

Figura 3: Relacionamento das dimensões da categoria satisfação com o orçamento.

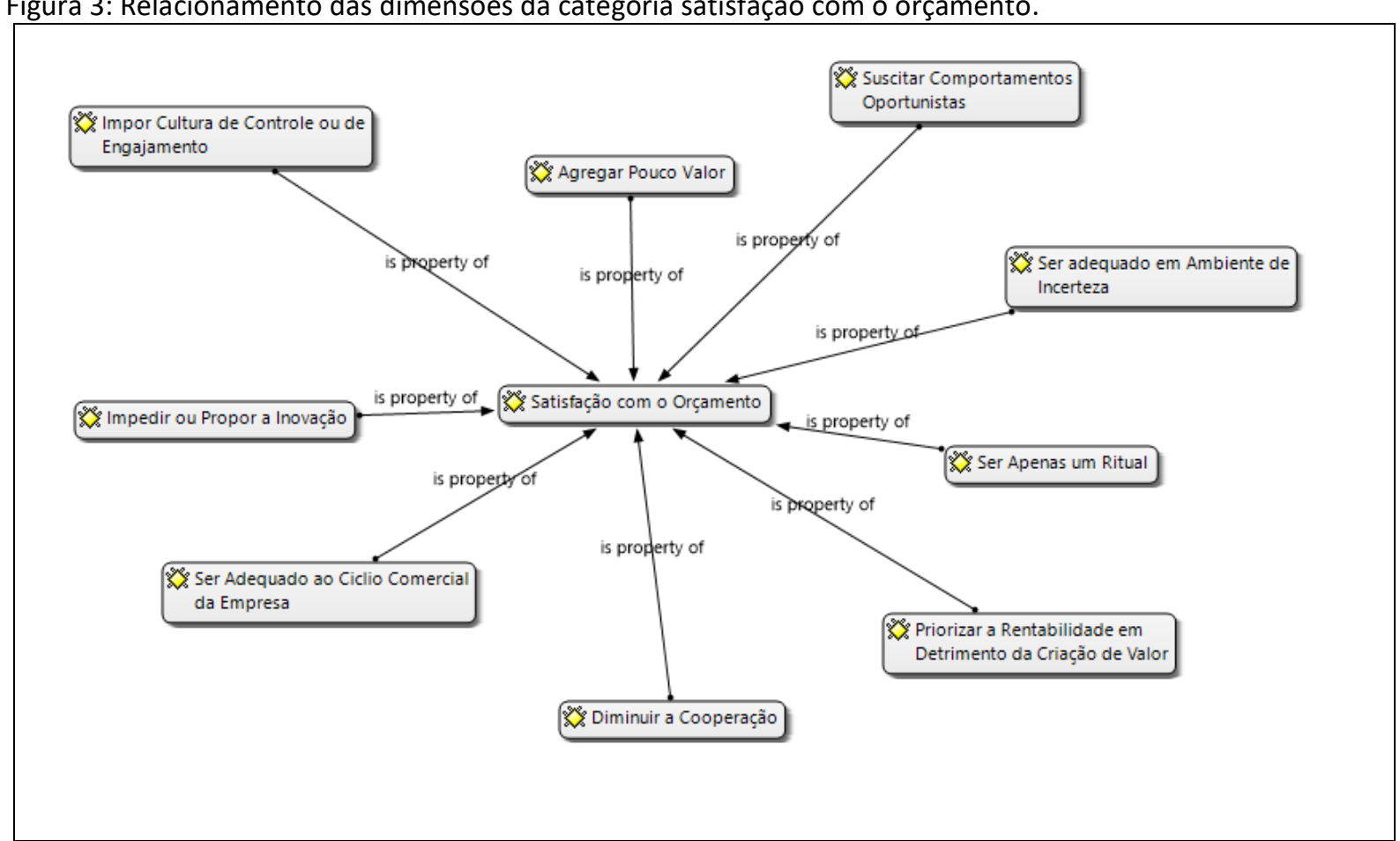

Fonte: os autores (2018).

Sendo a empresa uma consultoria empresarial, que atua com um ciclo fechado dentro do ano, e tendo em vista o fato de o orçamento ser discutido e reformulado, caso necessário, com certa periodicidade dentro do ano, conforme indicado pelos entrevistados, isso também indica um fator de satisfação, de acordo com Sponem e Lambert (2016), sobretudo ao se considerar que os entrevistados indicaram utilizar um orçamento de base zero, ou seja, que é totalmente reformulado ao início de cada clico operacional.

Outro fator de satisfação elencado por Sponem e Lambert (2016) presente nas falas dos entrevistados diz respeito a possibilidade de proporcionar comportamentos oportunistas, uma vez que ambos os responsáveis indicam para o fato de o processo orçamentário contribuir com seus objetivos pessoais:

principalmente a nível de conhecimento e também a nível financeiro, porque quando a gente consegue obter bons resultados, como redução de gastos, a gente consegue obter um retorno financeiro, então a gente acaba que consegue atingir os objetivos pessoais também (Entrevistado 1).

eu como gestor tenho que trazer resultados, e o resultado é composto por receitas e também controle dos gastos, e eu só consigo controlar meus gastos se eu tenho um orçamento bem elaborado para eu saber onde eu vou destinar o meu recurso, se eu não tivesse orçamento eu não conseguiria controlar meus gastos e consequentemente eu não conseguiria obter meu resultado, e se não obter meu resultado o meu desempenho profissional acaba sendo prejudicado, então o orçamento acaba ajudando neste aspecto (Entrevistado 2). 
Essas falas indicam que os entrevistados consideram que o processo orçamentário proporciona uma melhor visualização do seu desempenho e a afirmação do mesmo aos dirigentes da empresa, assim como a possibilidade de melhorias na parte remuneratória.

Foi feita também uma contagem das palavras mais citadas pelos entrevistados, e montada uma wordcloud que evidencia as palavras que mais se repetiram na fala dos entrevistados, evidenciada na Figura 4.

Figura 4: Wordcloud.

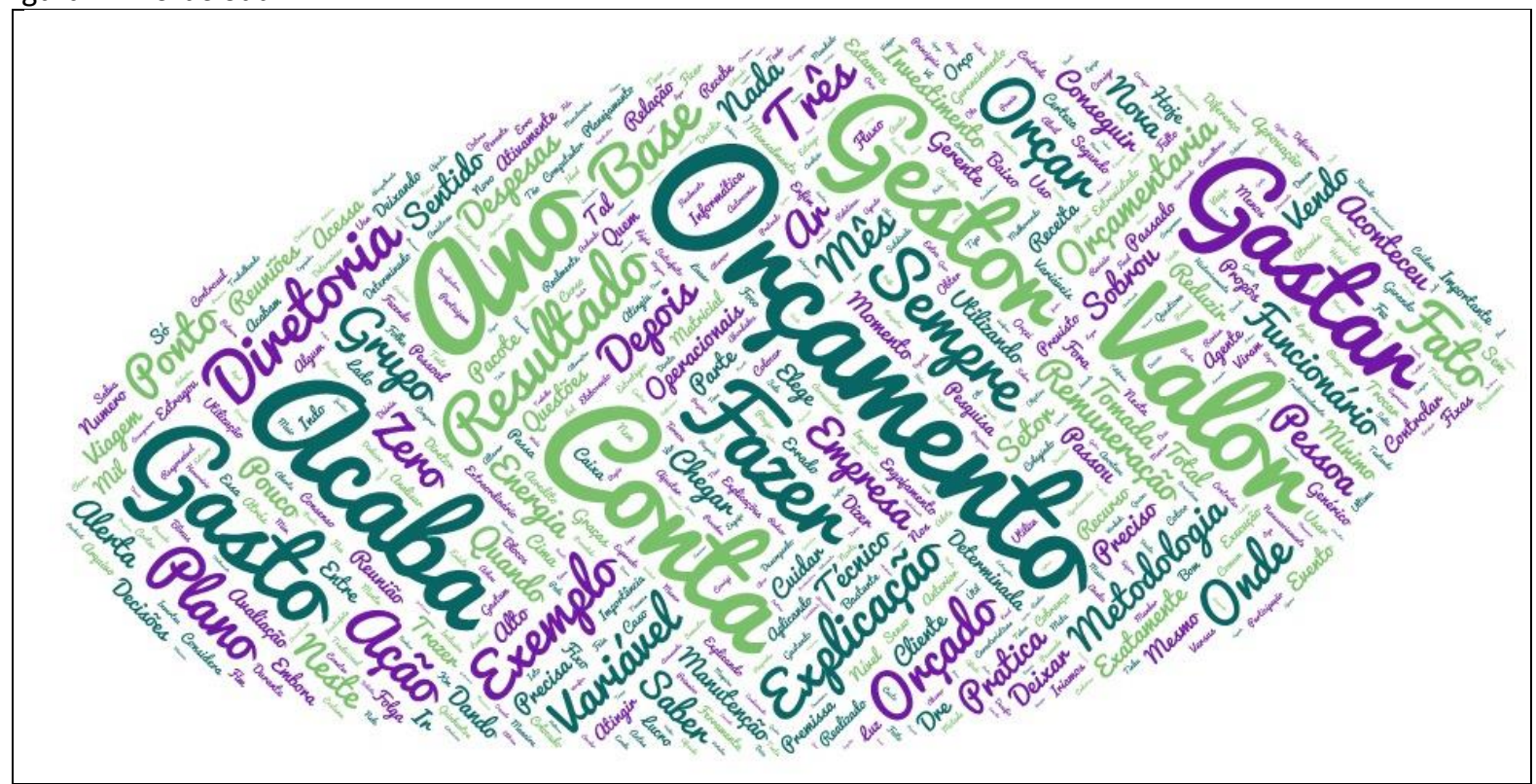

Fonte: os autores (2018).

A nuvem de palavras construída indica que entre as palavras mais vezes repetidas pelos entrevistados são "orçamento", "gastar", "valor", "conta" e "gasto", indicando a preocupação dos entrevistados com o controle financeiro proveniente da construção e aplicação dos orçamentos. Dessa forma, tendo sido feitas as análises das falas dos entrevistados, procede-se com as conclusões pertinentes ao estudo.

\section{CONSIDERAÇÕES FINAIS}

O tema proposto para este estudo centra-se no processo orçamentário das organizações, tendo como objetivo identificar como as características e funções dos orçamentos podem afetar a satisfação com o processo por parte dos seus responsáveis. Para tanto, foi feita uma adaptação do estudo de Sponem e Lambert (2016), através de um estudo qualitativo, aplicado aos dois responsáveis pelo processo orçamentário de uma organização de consultoria empresarial de consultoria localizada na cidade de Cascavel - PR, buscando identificar a relação entre as categorias de análise na referida organização.

A partir das respostas dos dois responsáveis pelo processo orçamentário da empresa foi possível verificar que determinadas características dos orçamentos e determinados usos promovem uma maior satisfação por parte dos envolvidos. A característica mais presente foi a da participação orçamentária, que apareceu e diversos momentos nas respostas, sendo inclusive citada por um dos entrevistados como um fator de satisfação, pois proporciona um maior engajamento e identificação com a organização.

Outra característica fortemente relacionada a satisfação com o processo orçamentário está no envolvimento dos componentes no processo, uma vez que o fato de os gestores se 
reunirem com a diretoria, tendo voz ativa na construção do processo orçamentário influencia também tanto no engajamento quanto na cooperação, fatores que causam satisfação.

Já no tocante as funções do orçamento, a principal geradora de satisfação é função de avaliação do desempenho através do orçamento, que apesar de ser uma função vinculada sobretudo à diretoria, causa satisfação nos componentes do processo, de modo que, ao alcançar as metas cumprir os objetivos vinculados ao orçamento, o participante mostra aos diretores seu comprometimento e sua capacidade perante a organização.

No mesmo sentido, o uso do orçamento como meio de remuneração causa satisfação de modo indireto, pois, mesmo o orçamento não sendo usado diretamente pela empresa para remunerar individualmente os gestores, o alcance de metas e redução de gastos leva a um melhor resultado global, o que é revertido em forma de remuneração variável.

Dessa forma, pode perceber que a satisfação com o processo orçamentário na empresa pesquisada refere-se sobretudo ao fator engajamento, uma vez que os responsáveis pelo processo mostram-se satisfeitos sobretudo pela possibilidade de estarem envolvidos, mostrando voz ativa e tomando parte no processo de gestão, bem como a possibilidade de, através do processo orçamentário, mostrar excelência na execução das atividades.

Assim, o trabalho contribuiu na definição de fatores capazes de gerar satisfação no processo orçamentário, de modo a permitir uma visão que pode ser aplicada nas empresas, de modo a proporcionar processos mais viáveis para as empresas, através do engajamento dos funcionários com o orçamento e, dessa forma, com a organização como um todo. 0 estudo avança as pesquisas no campo da contabilidade gerencial ao dar indícios que os orçamentos utilizados como ferramenta de apoio a gestão afetam a cultura organizacional das empresas, mesmo que de modo indireto, com achados como o fato de a avaliação de desempenhos dos gestores pela sua atuação no processo orçamentário ser fator de satisfação, mesmo não havendo a remuneração variável direta vinculada a esse processo. Desse modo, esse estudo indica que os orçamentos vão além de uma ferramenta de controle gerencial, podendo ser um meio para a criação de rotinas e cultura organizacional, fato esse que pode ser melhor explorado em pesquisas futuras.

Desse modo, outros trabalhos podem ser utilizados para a investigação dessa relação, como uma abordagem quantitativa das variáveis do estudo. Outra relação possível, seria o teste da endogenia entre a satisfação e as características e funções do orçamento, pois mesmo a satisfação sendo normalmente a variável dependente, ela também pode afetar as características e funções dos orçamentos, de modo que, quando insatisfeito com o processo, o participante pode alterar a forma como constrói ou utiliza o orçamento. Outra sugestão é, em um estudo qualitativo, abordar a visão também dos gestores operacionais envolvidos com o processo e dos diretores que o coordenam.

\section{REFERÊNCIAS}

ABERNETHY, M. A.; BROWNELL, P. The role of budgets in organizations facing strategic change: an exploratory study. Accounting, organizations and society, v. 24, n. 3, p. 189-204, 1999. DOI: https://doi.org/10.1016/S0361-3682(98)00059-2.

ARWIDI, O.; SAMUELSON, L. A. The development of budgetary control in Sweden-a research note. Management Accounting Research, v. 4, n. 2, p. 93-107, 1993. DOI: https://doi.org/10.1006/mare.1993.1007. 
BARDIN, L. Análise de conteúdo. 4. ed. Lisboa: Edições, v. 70, p. 1977, 2011.

BEDFORD, D. S.; MALMI, T. Configurations of control: An exploratory analysis. Management Accounting Research, v. 27, p. 2-26, 2015. DOI: https://doi.org/10.1016/j.mar.2015.04.002.

BONOMA, T. V. Case research in marketing: opportunities, problems, and a process. Journal of marketing research, p. 199-208, 1985. DOI:

https://doi.org/10.1177/002224378502200209.

BRUYNE, P. de; HERMAN, J.; SCHOUTHEETE, M. de. Os modos de investigação: o estudo de caso. In: Dinâmica da pesquisa em ciências sociais. Rio de Janeiro: Francisco Alves, 1977.

CANONICO, P.; SÖDERLUND, J. Getting control of multi-project organizations: combining contingent control mechanisms. International Journal of Project Management, v. 28, n. 8, p. 796-806, 2010. DOI: https://doi.org/10.1016/j.ijproman.2010.05.005.

CHAPMAN, C. S.; KIHN, L. A. Information system integration, enabling control and performance. Accounting, organizations and society, v. 34, n. 2, p. 151-169, 2009. DOI: https://doi.org/10.1016/j.aos.2008.07.003.

CHONG, K. M.; MAHAMA, H. The impact of interactive and diagnostic uses of budgets on team effectiveness. Management Accounting Research, v. 25, n. 3, p. 206-222, 2014. DOI: https://doi.org/10.1016/j.mar.2013.10.008.

COVALESKI, M.; AIKEN, M. Accounting and theories of organizations: some preliminary considerations. Accounting, Organizations and Society, v. 11, n. 4-5, p. 297-319, 1986. DOI: https://doi.org/10.1016/0361-3682(86)90002-4.

DERFUSS, K. The relationship of budgetary participation and reliance on accounting performance measures with individual-level consequent variables: a metaanalysis. European Accounting Review, v. 18, n. 2, p. 203-239, 2009. DOI: https://doi.org/10.1080/09638180802652371.

FISHER, J.; FREDERICKSON, J. R.; PEFFER, S. A. The effect of information asymmetry on negotiated budgets: An empirical investigation. Accounting, Organizations and Society, v. 27, n. 1-2, p. 27-43, 2002. DOI: https://doi.org/10.1016/S0361-3682(01)00046-0.

FISHER, J. G.; FREDERICKSON, J. R.; PEFFER, S. A. Budget negotiations in multi-period settings. Accounting, Organizations and Society, v. 31, n. 6, p. 511-528, 2006. DOI: https://doi.org/10.1016/j.aos.2005.12.008.

FREZATTI, F. Orçamento empresarial: planejamento e controle gerencial. São Paulo: Atlas, 2000.

FROW, N.; MARGINSON, D.; OGDEN, S. "Continuous" budgeting: Reconciling budget flexibility with budgetary control. Accounting, Organizations and Society, v. 35, n. 4, p. 444461, 2010. DOI: https://doi.org/10.1016/j.aos.2009.10.003. 
HANSEN, S. C.; VAN DER STEDE, W. A. Multiple facets of budgeting: an exploratory analysis. Management accounting research, v. 15, n. 4, p. 415-439, 2004. DOI: https://doi.org/10.1016/j.mar.2004.08.001.

HOPE, J.; FRASER, R. Beyond budgeting: how managers can break free from the annual performance trap. Cambrige: Harvard Business Press, 2003.

LIBBY, T.; LINDSAY, R. M. Beyond budgeting or budgeting reconsidered? A survey of NorthAmerican budgeting practice. Management accounting research, v. 21, n. 1, p. 56-75, 2010. DOI: https://doi.org/10.1016/j.mar.2009.10.003.

MAHER, Mohammad Hadi; FAKHAR, Mohammad Sadegh; KARIMI, Zohreh. The relationship between budget emphasis, budget planning models and performance. Journal of Health Management and Informatics, v. 5, n. 1, p. 16-20, 2018.

MAIGA, A. S. F. Budget satisfaction, and budget performance: a path analytic model of their relationships. In: Advances in Accounting Behavioral Research. Bingley: Emerald Group Publishing Limited, 2006. p. 87-111.

MALMI, T.; BROWN, D. A. Management control systems as a package-Opportunities, challenges and research directions. Management accounting research, v. 19, n. 4, p. 287300, 2008. DOI: https://doi.org/10.1016/j.mar.2008.09.003.

MERCHANT, K. A. The design of the corporate budgeting system: influences on managerial behavior and performance. Accounting Review, p. 813-829, 1981. DOI: https://www.jstor.org/stable/247203.

MERCHANT, K. A.; MANZONI, J. F. The achievability of budget targets in profit centers: A field study. In: Readings in Accounting for Management Control. Boston: Springer, 1989. p. 496520.

OTLEY, D.; FAKIOLAS, A. Reliance on accounting performance measures: dead end or new beginning? Accounting, Organizations and Society, v. 25, n. 4-5, p. 497-510, 2000. DOI: https://doi.org/10.1016/S0361-3682(98)00007-5.

SHIELDS, J. F.; SHIELDS, M. D. Antecedents of participative budgeting. Accounting, Organizations and Society, v. 23, n. 1, p. 49-76, 1998. DOI: https://doi.org/10.1016/S03613682(97)00014-7.

SILVA, A. M. Dinâmica da produtividade do setor de serviços no Brasil: uma abordagem microeconômica. In: De NEGRI, JA; KURBOTA, LC Estrutura e dinâmica do setor de serviços no Brasil. Brasília, 2006.

SIMONS, R. Levers of control: how managers use innovative control systems to drive strategic renewal. Cambrige: Harvard Business Press, 1995. 
SPONEM, S.; LAMBERT, C. Exploring differences in budget characteristics, roles and satisfaction: A configurational approach. Management Accounting Research, v. 30, p. 47-61, 2016. DOI: https://doi.org/10.1016/j.mar.2015.11.003.

UENO, S.; SEKARAN, U. The influence of culture on budget control practices in the USA and Japan: An empirical study. Journal of International Business Studies, v. 23, n. 4, p. 659-674, 1992. DOI: https://doi.org/10.1057/palgrave.jibs.8490282.

VAN VEEN-DIRKS, P. Different uses of performance measures: The evaluation versus reward of production managers. Accounting, Organizations and Society, v. 35, n. 2, p. 141-164, 2010. DOI: https://doi.org/10.1016/j.aos.2009.02.002.

YIN, R. K. Estudo de caso: planejamento e métodos. 4 ed. Porto Alegre: Bookman, 2010. 